\title{
CARDIO-AORTIC FISTULA WITH MULTIPLE CONGENITAL ANOMALIES IN A 71-YEAR-OLD MAN
}

\author{
BY \\ T. D. O'BRIEN AND I. J. L. GOLDBERG \\ From the Geriatric Department, Oldham and District General Hospital, Oldham
}

A case of congenital pulmonary stenosis, ventricular septal defect, and ruptured aortic sinus aneurysm in a 71-year-old man is reported. We have been unable to find an account of any similar case.

\section{Case Report}

At 28 years of age the patient had complained of moderate (grade III) dyspnœa on exertion and subsequently this had limited him to light work. He had remained well until a few months before admission, when he had noted swelling of his feet and legs for the first time. Despite treatment by his doctor the œdema had persisted and he was admitted to hospital on February 4, 1960.

Clinical examination showed a youthful looking man in spite of his 71 years, with pitting œdema of both feet and legs to the level of the knees. He appeared pale and lightly jaundiced. There was increased filling of his neck veins to the level of the angle of the jaw in the sitting position. The pulse was 80 a minute and pulsus bigeminus was present. The blood pressure was 155/70. The cardiac impulse was palpable in the fifth intercostal space at the anterior axillary line. Systolic retraction occurred over the apex and was accompanied by a præcordial heave. A single second sound was clearly heard over the second left intercostal space about $5 \mathrm{~cm}$. from the centre of the sternum. A very loud, harsh, systolic murmur covering the first heart sound was heard maximally in the third left intercostal space, extending from the left sternal edge to the mid clavicular line and this was accompanied by an obvious systolic thrill. The murmur was not heard at the apex and finished abruptly in the second left intercostal space : it continued into late systole, but seemed to finish before the second sound. A very soft diastolic murmur was also present over the third intercostal space $5 \mathrm{~cm}$. from the left border of the sternum.

Examination of the patient's remaining systems did not show any abnormality, apart from the signs of a right-sided pleural effusion and an enlarged liver. The serum bilirubin was $1.8 \mathrm{mg}$. per $100 \mathrm{ml}$. with a positive direct Van den Bergh reaction. Further investigations including analysis of the urine, blood urea, a full blood count, erythrocyte sedimentation rate, and additional liver function tests showed no abnormality. A chest X-ray confirmed the presence of a right-sided pleural effusion and disclosed patchy consolidation in the right lower zone. A cardiogram showed non-specific changes: there was sinus rhythm with ventricular premature beats and the transitional zone was rotated to the left and the $T$ waves were of low voltage in all leads.

The patient died seven days after admission. Death was due to bronchopneumonia and heart failure.

Post-mortem Findings. A large right pleural effusion, pulmonary œdema, and right-sided bronchopneumonia were found. The kidneys, spleen, and liver showed signs of venous congestion. Diverticulosis of the colon was present.

The heart was greatly enlarged (weight 720 g.). An aneurysm of the right coronary sinus had ruptured into the conus of the right ventricle between the right and left posterior cusps of the pulmonary valve, $5 \mathrm{~cm}$. below the commissure (Fig. 1). A slit-like tear of the aorta, $2.8 \mathrm{~cm}$. long, extended superiorly from the aneurysm. If the two edges of the slit were juxtaposed, a small, round orifice with a thickened edge and a circumference of $0.25 \mathrm{~cm}$. was formed, communicating between the aorta and the conus of the right ventricle. A defect of the bulbar portion of the ventricular septum was present (Fig. 2). It was $1.2 \mathrm{~cm}$. in length and lay transversely just below the level of the right coronary cusp of the aortic valve and below and medial to the left posterior cusp of the pulmonary valve. The pulmonary valve was stenosed $(2.5 \mathrm{~cm}$. in circumference). 


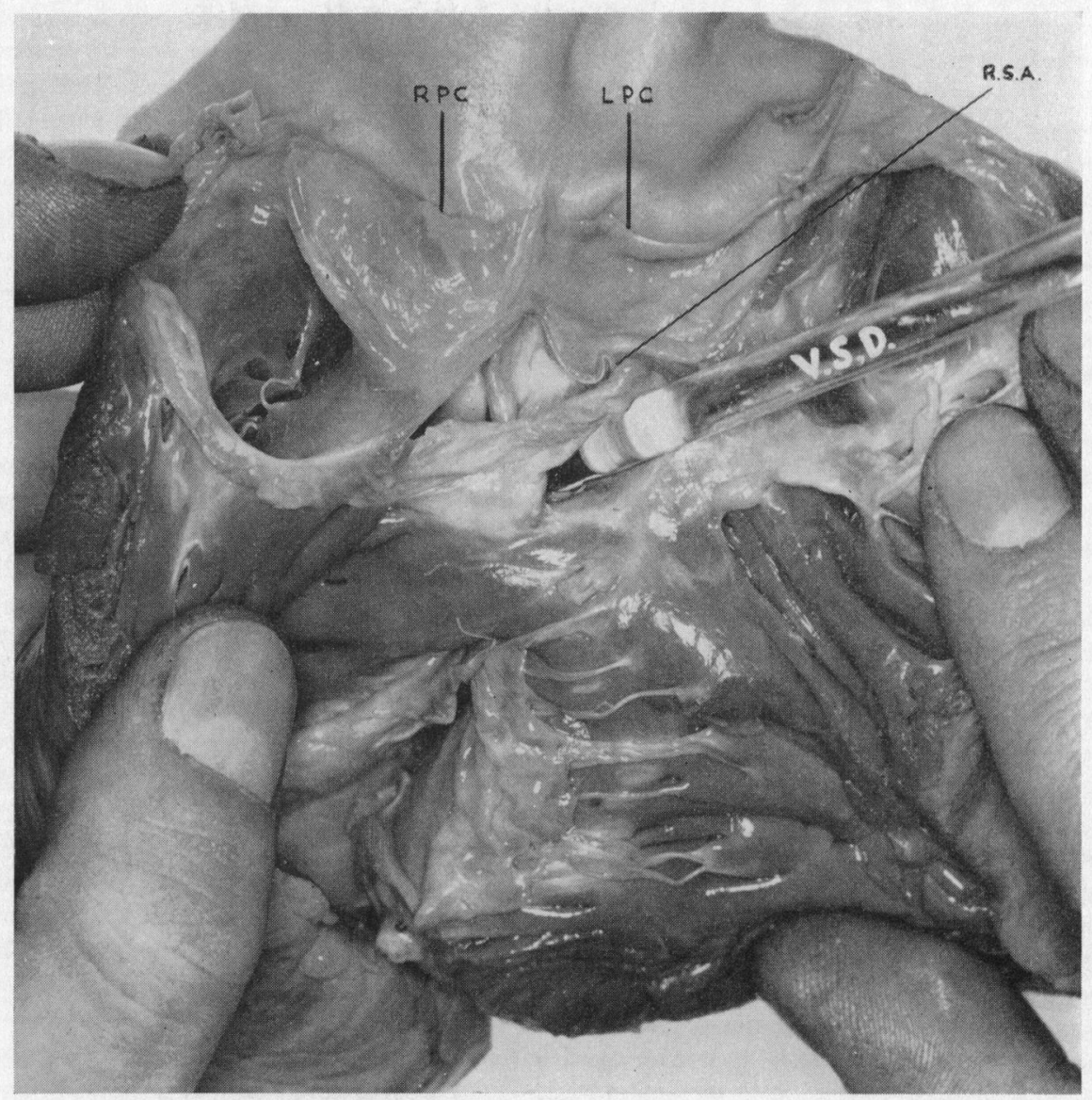

FIG. 1.-The right ventricle showing the pulmonary artery with the right (R.P.C.) and left (L.P.C.) posterior cusps of the pulmonary valve, the ruptured aortic sinus aneurysm (R.S.A.), and the ventricular septal defect (V.S.D.)

No calcification was present in the valve. A fibrotic ring of connective tissue was present about $2 \mathrm{~cm}$. below the valve. The right coronary cusp of the aortic valve showed some calcification.

The aorta was in its normal position in relation to the ventricular septum. The coronary arteries and aorta showed less atheroma than is usually found at this age. Both ventricles were hypertrophied and dilated, the right relatively more than the left. Both atria were also dilated.

Histologically, the walls of the aneurysm consisted of fibrous and muscular tissue. There was no evidence of syphilitic arteritis and no calcification.

\section{Discussion}

In pulmonary stenosis with ventricular septal defect the main problem is the diagnosis of the pulmonary stenosis (Eldridge and Hultgren, 1955). The prominent vascular lung markings and a loud pulmonary second sound may result in the pulmonary stenosis being mis-diagnosed. Rudolf $e t$ al . (1954) suggested that the combination might be suspected by the presence of a systolic murmur and thrill at the lower left sternal border in addition to the systolic murmur heard at the pulmonary area.

Rupture of an aneurysm of the aortic sinus into the right side of the heart is associated with a murmur that Oram and East (1955) have described as "usually loud, harsh and superficial in charac- 


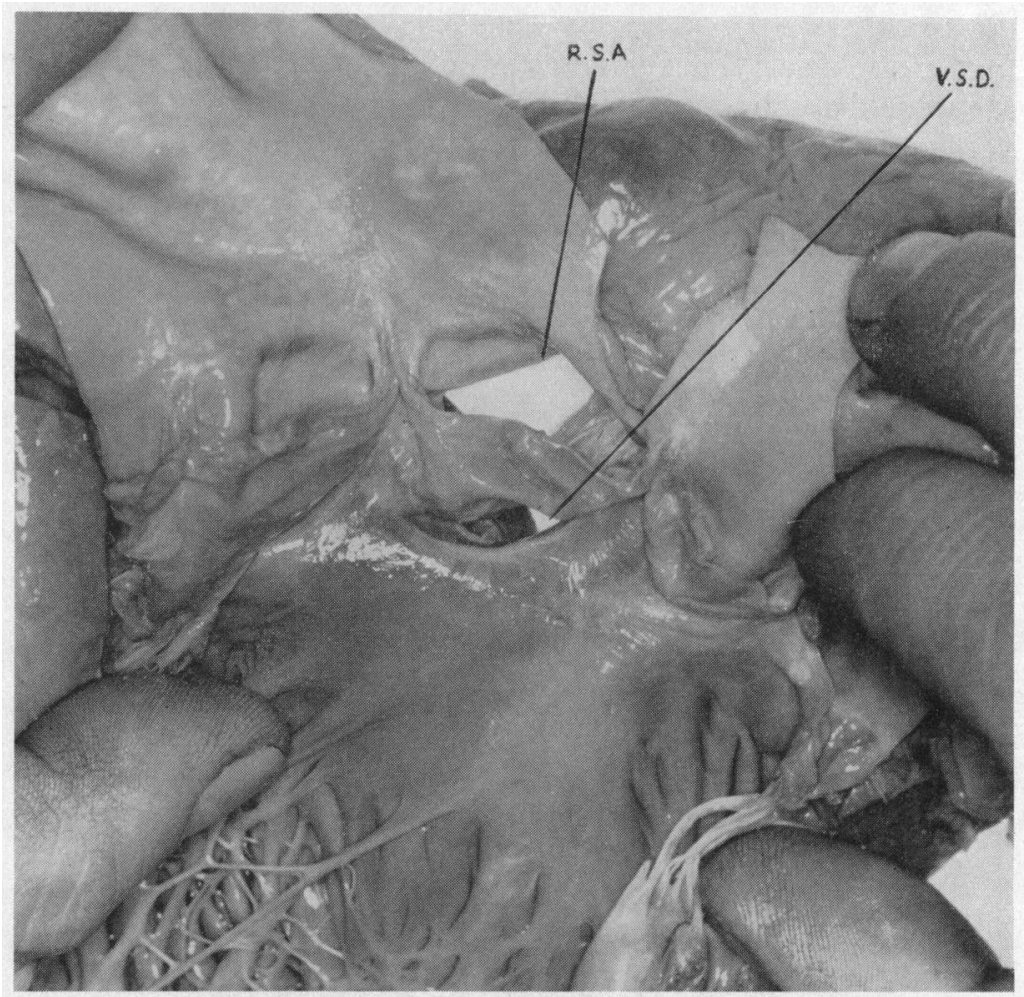

FIG. 2.-The left ventricle showing the aortic valve cusps, the ruptured aortic sinus aneurysm (R.S.A.), and the ventricular defect (V.S.D.).

ter, and accompanied by a coarse thrill. As a rule it is best heard near the centre of the sternum or a little to the left of it in the second, third, or fourth intercostal spaces. It characteristically occupies both phases of the cardiac cycle, either as a to and fro or a continuous noise and the accentuation may be on systole or diastole." They suggest that both the systolic and diastolic elements of the murmur may be due to a flow of blood through the ruptured orifice of the aneurysm.

In our case the absence of central cyanosis, finger clubbing, raised hæmoglobin, and raised packed cell volume, indicated a left-to-right shunt. It is usual in cases of cardio-aortic fistula to hear a continuous murmur. In our case pulsus bigeminus and loud respiratory sounds interfered with auscultation, so we cannot exclude a continuous murmur with certainty. The systolic thrill and murmur were probably due to the pulmonary valve stenosis, aortico-cardiac fistula, and ventricular septal defect. The diastolic murmur, as Oram and East (1955) have suggested was probably due to aortic blood flowing back through the perforation into the pulmonary conus.

Only one case of aortic sinus aneurysm and pulmonary conus stenosis has been reported (King, 1942). Congenital pulmonary stenosis and ventricular septal defect are not uncommonly associated (Wood, 1956). The present case shows all three anomalies. The main point of interest about this patient is that he survived into the eighth decade. Among the 25 cases of aortic sinus aneurysm reviewed by Morgan Jones and Langley (1949), 10 had ventricular septal defects: they observed that the heart tolerates a congenital cardio-aortic fistula much better than one acquired in later life. The outlook for ventricular septal defect is better when there is a co-existent pulmonary stenosis (Brotmacher and Campbell, 1958). Our case with his remarkable longevity seems to support these two opinions. 


\section{Summary}

The clinical and pathological findings in a case of congenital pulmonary stenosis, ventricular septal defect, and ruptured aortic sinus aneurysm in a 71-year-old man are described. An explanation of the clinical findings and longevity is suggested.

We wish to thank Dr. W. H. Lloyd for permission to publish this case and for his advice and encouragement, Dr. A. Morgan Jones and Dr. P. Wood for reading and commenting on the case and Mr. C. Richardson, Photographic Department, for his generous assistance.

\section{References}

Brotmacher, L., and Campbell, M. (1958). Brit. Heart J., $20,97$.

Eldridge, F. L., and Hultgren, H. N. (1955). Amer. Heart J., 49, 838.

Jones, A. M., and Langley, F. A. (1949). Brit. Heart J., 11, 325.

King, J. T. (1942). Principles and Practice of Cardiology. Bramwell and King, Oxford, p. 311.

Oram, S., and East, T. (1955). Brit. Heart J., 17, 541.

Rudolph, A. M., Nadas, A. S., and Goodale, N. T. (1954). Amer. Heart J., 48, 808.

Wood, P. (1956). Diseases of the Heart and Circulation. 2nd ed., Eyre and Spottiswoode, London. 